\title{
Experiment and simulation of single inhibitor SH110 for void-free TSV copper filling
}

\author{
Fuliang Wang ${ }^{1,2}$ \& Yuping Le $\mathrm{e}^{1,2,3 凶}$
}

Three-dimensional integration with through-silicon vias (TSVs) is a promising microelectronic interconnection technology. Three-component additives are commonly used for void-free TSV filling. However, optimising the additive concentrations is an expensive process. To avoid this, a singlecomponent additive was developed: 3-(2-(4,5-dihydrothiazol-2-yl) disulfanyl) propane-1-sulfonic acid/ sulfonate (SH110). Sodium 3, $3^{\prime}$-dithiodipropane sulfonate (SPS) and SH110 were used as additives for TSV electroplating copper filling. SH110 resulted in void-free filling, whereas large keyhole voids were found for SPS. To understand how the additives affect the filling mechanism, linear sweep voltammetry of the plating solutions was carried out. The interactions between the Cu surface and additives were simulated by molecular dynamics (MD) analysis using Materials Studio software, and quantum chemistry calculations were conducted using GAUSSIAN 09W. SH110 adsorbs to the Cu surface by both 4,5-dihydrothiazole (DHT) and 3-mercaptopropane sulfonate (MPS) moieties, while SPS is adsorbed only by MPS moieties. MD simulations indicated that the adsorption of the coplanar MPS moiety is the main factor governing acceleration. Quantum chemistry calculations showed that DHT provides an inhibitory effect for TSV filling, while MPS acts as an accelerator for SH110. SH110 is an excellent additive exhibiting both the acceleration and the suppression necessary for achieving void-free TSV filling.

Three-dimensional (3D) integration with through-silicon vias (TSVs) is a promising technology for use in electronic systems, as TSVs can provide extremely short vertical interconnections that can improve performance, increase operating speed, and reduce the volume of devices when compared with conventional integration technologies ${ }^{1-3}$. TSV copper filling is one of the key techniques used for TSV fabrication, as it costs $\sim 40 \%$ less than conventional integration technologies. However, voids often occur upon filling, which must be overcome for reliable TSV fabrication ${ }^{4,5}$.

To accomplish void-free TSV filling, an accelerator, suppressor, and leveller are commonly added to the plating solution. At present, the most commonly used accelerator is sodium 3,3'-dithiodipropane sulfonate (SPS) ${ }^{6}$, where the sulfur S-S bonds and sulfonic acid or sulfonate groups $\left(\mathrm{SO}_{3} \mathrm{H}_{\text {or }} \mathrm{SO}_{3}{ }^{-}\right)$are thought to be the key structures responsible for acceleration effects. The typical leveller employed is an organic monomer containing positively charged nitrogen, such as pyridinium, imidazolium, or ammonium ${ }^{7,8}$. Polyethylene glycol (PEG), polypropylene glycol (PPG), and co-polymers thereof are commonly used as suppressor additives ${ }^{9,10}$. These additives accelerate the via bottom deposition rate and suppress the via mouth deposition rate, to obtain bottomup filling. However, it takes numerous experiments to optimise the concentrations of each component in this complex additive system. Therefore, a single inhibitor that accomplishes void-free TSV filling is needed in order to reduce the time and cost of the optimisation process. Thus far, only one report, by Tang and co-workers, has demonstrated a single-component additive (Janus Green B) that could provide void-free filled-in micro-vias ${ }^{11}$.

In this study, a single inhibitor, 3-(2-(4,5-dihydrothiazol-2-yl)disulfanyl)propane-1-sulfonic acid (SH110), was found to possess the ability to fill the TSV without introducing voids. Linear sweep voltammetry (LSV) was performed to determine the electrochemical properties of additives in the deposition process for TSV filling. To understand how SH110 affects the TSV filling mechanism, molecular dynamics (MD) simulations and quantum chemical calculations were used to analyse the configuration and electronic structure of SH110 and its interactions with the copper surface, in comparison with a common accelerator, SPS.

\footnotetext{
${ }^{1}$ School of Mechanical and Electrical Engineering, Central South University, Changsha 410083, HN Province, People's Republic of China. ${ }^{2}$ State Key Laboratory of High Performance Complex Manufacturing, Changsha 410083, People's Republic of China. ${ }^{3}$ School of Mechanical and Electrical Engineering, Guilin University of Electrical Technology, Guilin, People's Republic of China. ${ }^{\square}$ email: leyuping1@163.com
} 
a

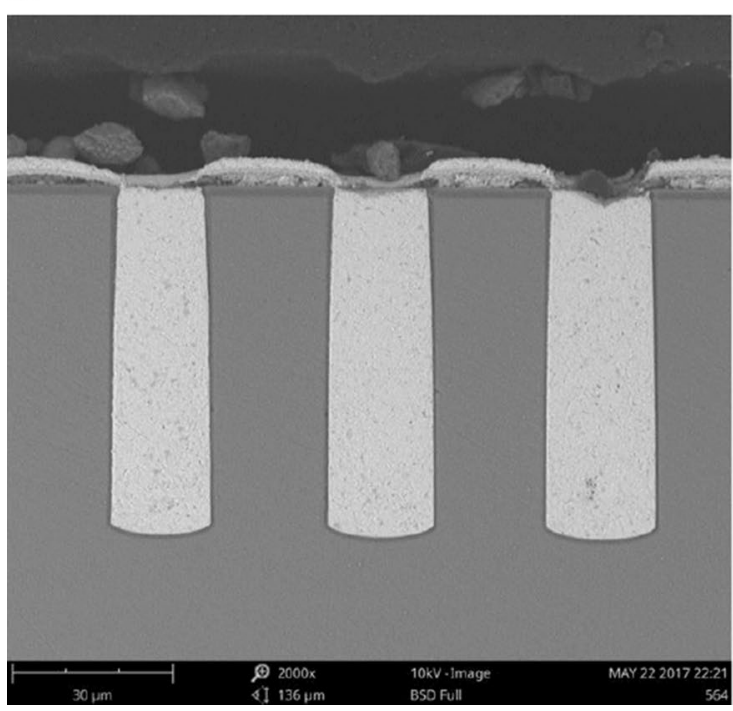

b

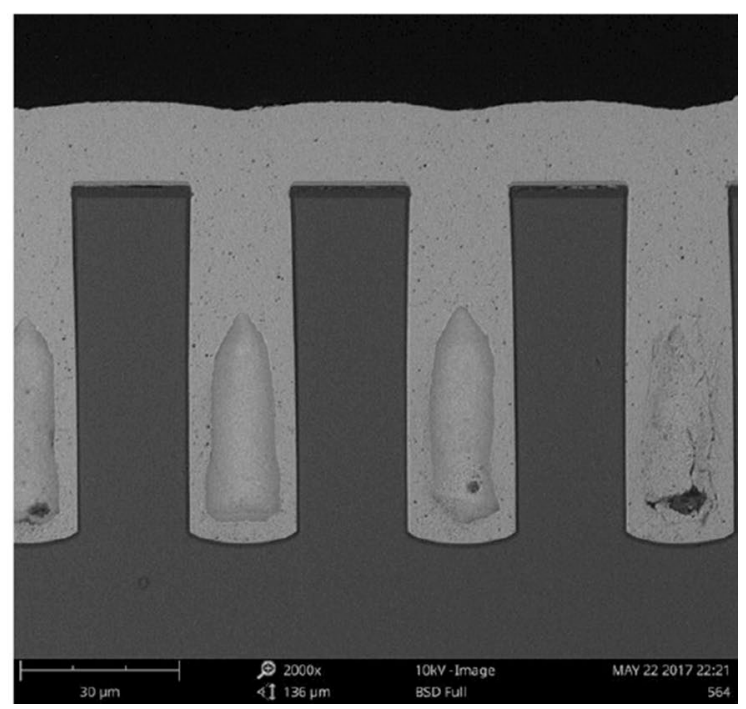

Figure 1. Vertical cross-sectional SEM image of TSV filling results with accelerators. (a) SH110 and (b) SPS (TESCAN VEGA 3 https://www.tescan.com/).

\section{Results and discussion}

Electroplating. SH110 and SPS were separately used as additives for TSV electroplating. Vertical crosssectional scanning electron microscopy (SEM) images of the filled TSVs are shown in Fig. 1a,b. The applied electroplating current density was $1 \mathrm{~mA} / \mathrm{cm}^{2}$ with plating times of $12 \mathrm{~h}$. Using SH110 as the additive, the TSVs were fully filled without any voids, as shown in Fig. 1a. The thin film on top of the silicon indicates that these vias were filled in a bottom-up manner. However, for the sample with SPS as the additive, large keyhole voids were found, as shown in Fig. 1b. Thus, SH110 provides excellent filling behaviour.

To better understand how the SH110 additive facilitated void-free TSV filling, TSVs filled at different plating times were obtained, as shown in Fig. 2. (Note that, as we designed five different pitches for the vias in the same die, the pitches of the vias in Fig. 2 vary.) Initially ( $2 \mathrm{~h}$, Fig. $2 \mathrm{a})$, the TSVs were only plated at the bottom, following the U-shaped model; copper deposition was almost totally suppressed in the top half of the vias. Over time ( 3 h, Fig. 2b), the thickness of the copper at the bottom half of the vias increased, whereas the top half of the via remained suppressed. Then, after the bottom half of the vias were completely filled ( $8 \mathrm{~h}$, Fig. $2 \mathrm{c})$, copper began to be deposited in the top half in a bottom-up manner. The entire vias were fully filled after $12 \mathrm{~h}$ (Fig. 2d).

Therefore, with the single inhibitor SH110, the TSVs were filled according to different models at different stages in the filling process. The first stage is the filling of the bottom half of the vias, which proceeds by the U-shape model; the top half of the vias are filled in the second stage, following the bottom-up model. It should be noted that the thickness of the deposited copper layer at the surface remained unchanged with time, indicative of total suppression of the surface.

Figures 1 and 2 is generate by Scanning electron microscope (SEM) (TESCAN VEGA 3 https://www.tescan. $\mathrm{com} /$ ). SEM is used to observe the cross section of TSV copper plating filling. The TSV hole was magnified by 2000-3000 times. Electron microscope was used to take photos directly.

Electrochemical procedures. To understand how the additives affect the filling mechanism for TSVs, LSVs was performed using plating solutions with either SH110 or SPS additives, as shown in Fig. 3 and Table 1. According to the additive theory, a large peak current density $\left(\mathrm{I}_{\mathrm{p}}\right)$ means acceleration plays a leading role, whereas a large valley $\left(I_{b}\right)$ suggests that suppression is predominant. Thus, a larger $\Delta I$ value $\left(I_{p}-I_{b}\right)$ indicates better bottom-up filling ability in TSVs, and a larger $\Delta \mathrm{E}$ (the potential gap between $\mathrm{I}_{\mathrm{p}}$ and $\mathrm{I}_{\mathrm{b}}$ ) indicates that there is a wider potential region accessible for bottom-up filling ${ }^{12,13}$.

For the primary solution containing $\mathrm{SH} 110$, the peak current density $\left(\mathrm{I}_{\mathrm{p}}=0.859 \mathrm{~A} / \mathrm{cm}^{2}\right)$ appears at approximately $-0.250 \mathrm{~V}$, with a valley $\left(\mathrm{I}_{\mathrm{b}}=0.567 \mathrm{~A} / \mathrm{cm}^{2}\right)$ at approximately $-0.521 \mathrm{~V}$. For the plating solution with SPS, the peak current density $\left(\mathrm{I}_{\mathrm{p}}=1.03 \mathrm{~A} / \mathrm{cm}^{2}\right)$ appears at approximately $-0.314 \mathrm{~V}$, with a valley $\left(\mathrm{I}_{\mathrm{b}}=0.91 \mathrm{~A} / \mathrm{cm}^{2}\right)$ at approximately $-0.397 \mathrm{~V}$. Moreover, the $\Delta \mathrm{I}$ and $\Delta \mathrm{E}$ values of the solution with $\mathrm{SH} 110$ are $0.292 \mathrm{~A} / \mathrm{cm}^{2}$ and $0.271 \mathrm{~V}$, respectively, which are both greater than those with SPS $\left(0.12 \mathrm{~A} / \mathrm{cm}^{2}\right.$ and $0.073 \mathrm{~V}$, respectively).

Therefore, SH110 provides better bottom-up filling ability than SPS, as it has better suppression effects at high-potential locations, such as the via mouth. The larger $\Delta \mathrm{E}$ of SH110 also means it has a wider potential operation window than SPS. Employing SH110 as a solitary additive results in a fully filled TSV, while the SPS additive results in keyhole voids (Fig. 1).

Molecular dynamics simulation. Since the adsorption characteristics of additives are intrinsically linked to their role in TSV filling, MD simulations were performed to study the adsorption behaviour of SPS and $\mathrm{SH} 110$ on $\mathrm{Cu}$ (001), $\mathrm{Cu}(101)$ and $\mathrm{Cu}$ (111) surface. Because SPS and SH110 are involved in the filling process of 
a

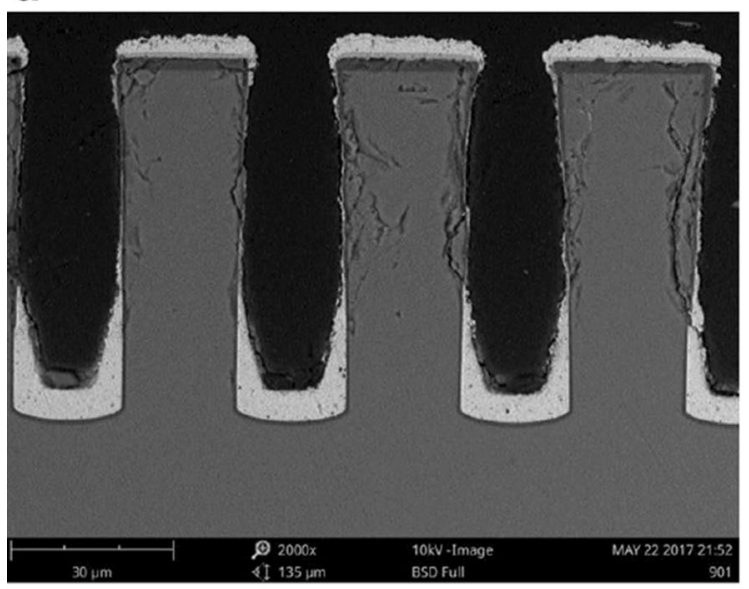

C

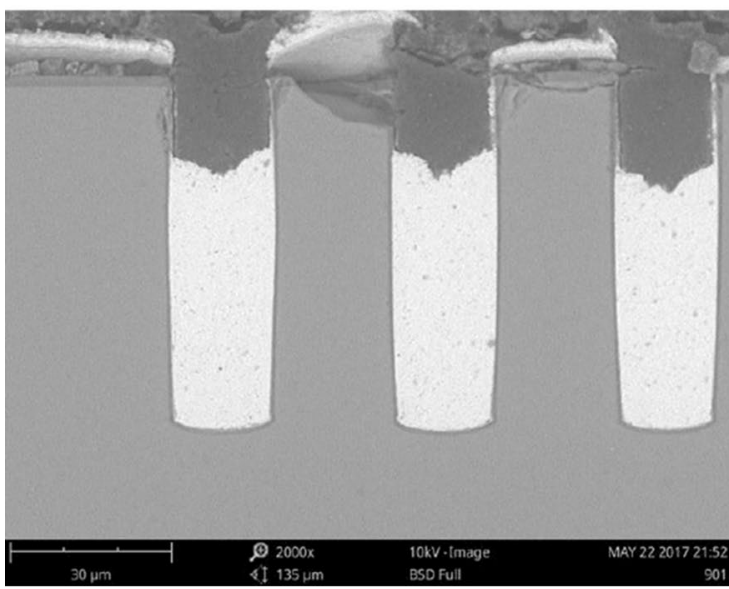

b

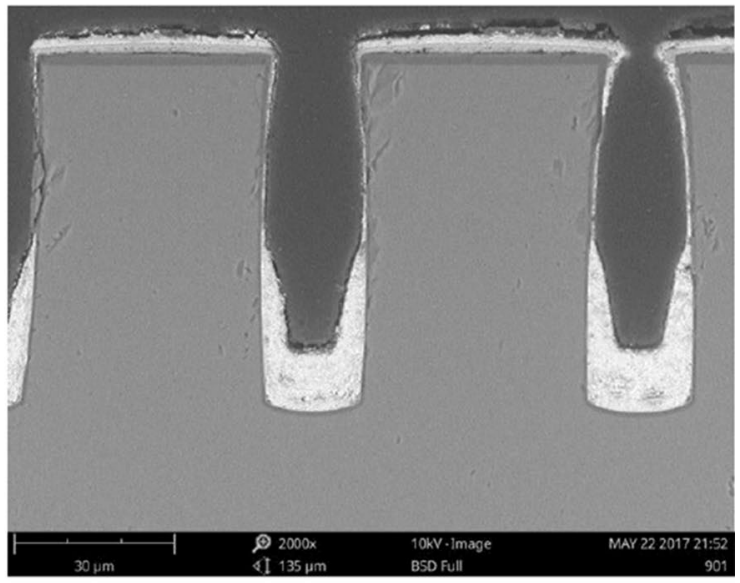

d

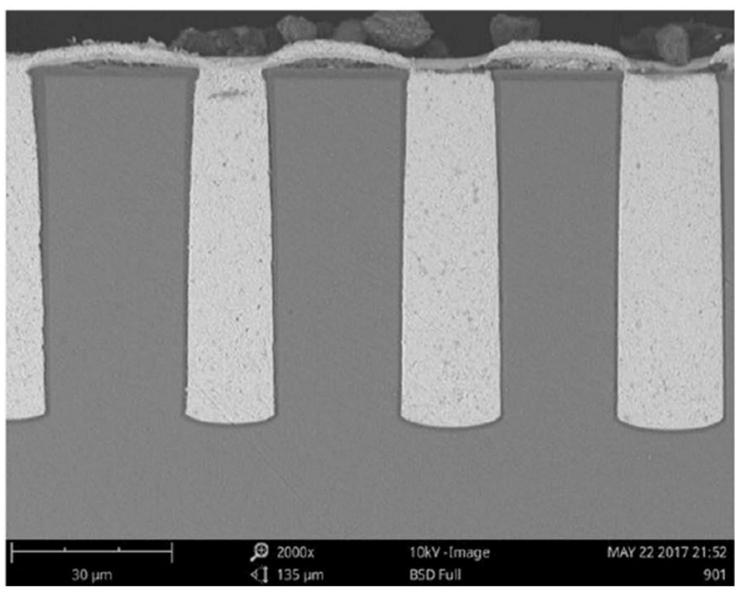

Figure 2. Vertical cross-sectional SEM images of TSVs filled using SH110 additive at different times. (a) $2 \mathrm{~h}$, (b) $3 \mathrm{~h},(\mathbf{c}) 8 \mathrm{~h}$, and (d) $12 \mathrm{~h}$ (TESCAN VEGA 3 https://www.tescan.com/).
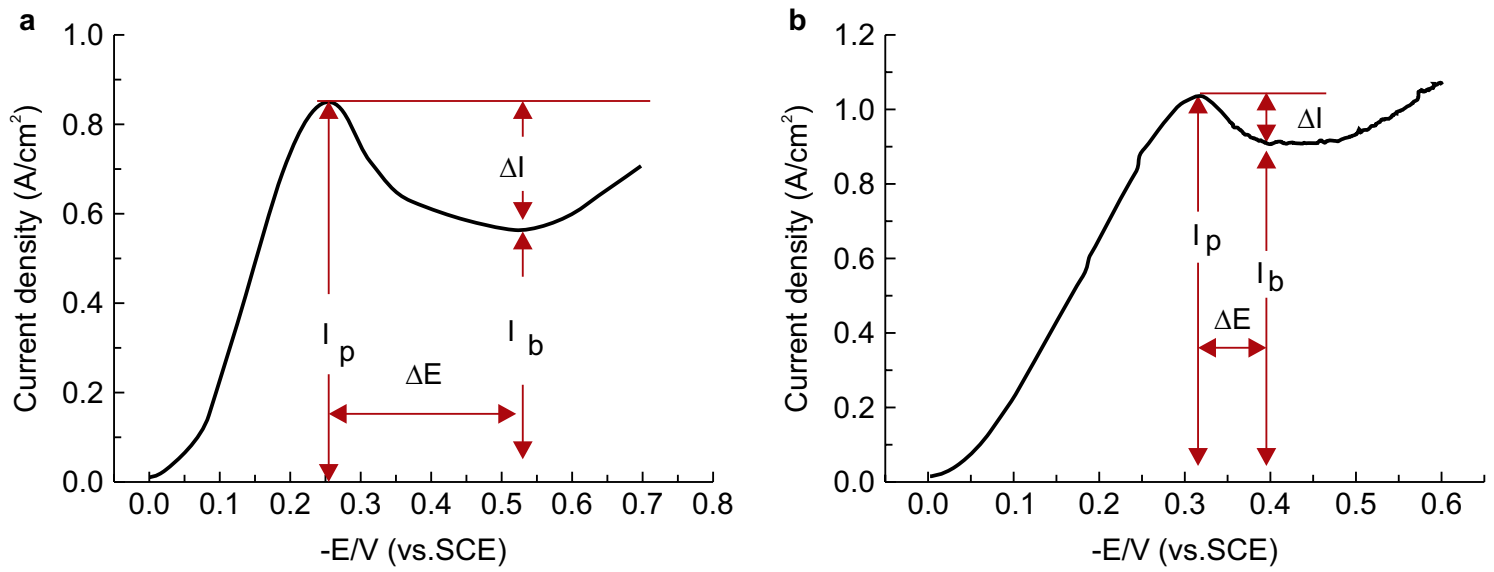

Figure 3. LSV measured in the plating bath. (a) Plating solution with SH110 and (b) plating solution with SPS.

electroplated copper, the surfaces most likely to be contacted are the surface of $\mathrm{Cu}$ (111), the surface of $\mathrm{Cu}(111)$ and the surface of copper during the filling process of electroplated copper, the main consideration in the filling process of TSV is (111).

Figure $4 \mathrm{a}-\mathrm{d}$ show the initial and equilibrium stages for adsorption of SPS. It can be seen that In the initial state onCu (111) (Fig. 4a), the MPS groups are oriented away from the copper surface, thus giving the SPS molecule a V-shape. SPS is adsorbed coplanar to the copper surface when in equilibrium on Cu (001) (Fig. 4b). SPS 


\begin{tabular}{|l|r|r|}
\hline & SH110 & \multicolumn{1}{l|}{ SPS } \\
\hline $\mathrm{I}_{\mathrm{p}}\left(\mathrm{A} / \mathrm{cm}^{2}\right)$ & 0.859 & 1.030 \\
\hline $\mathrm{I}_{\mathrm{b}}\left(\mathrm{A} / \mathrm{cm}^{2}\right)$ & 0.567 & 0.910 \\
\hline $\mathrm{E}_{\mathrm{p}}$ & -0.250 & -0.314 \\
\hline $\mathrm{E}_{\mathrm{b}}$ & -0.521 & -0.397 \\
\hline$\Delta \mathrm{I}\left(\mathrm{A} / \mathrm{cm}^{2}\right)$ & 0.292 & 0.120 \\
\hline$\Delta \mathrm{E}(\mathrm{V})$ & 0.271 & 0.073 \\
\hline
\end{tabular}

Table 1. Liner sweep voltammetry (LSV) results of SPS and SH110 electroplating solutions.

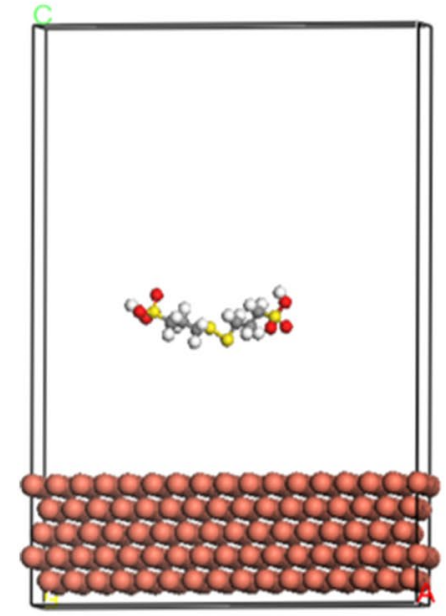

(a) initial

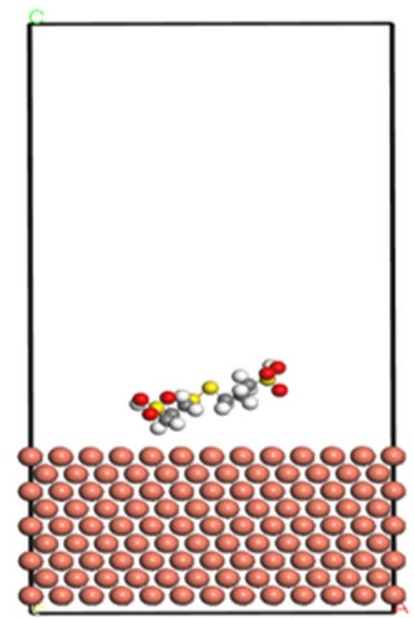

(b) $\mathrm{Cu}\left(\begin{array}{lll}0 & 0 & 1\end{array}\right)$

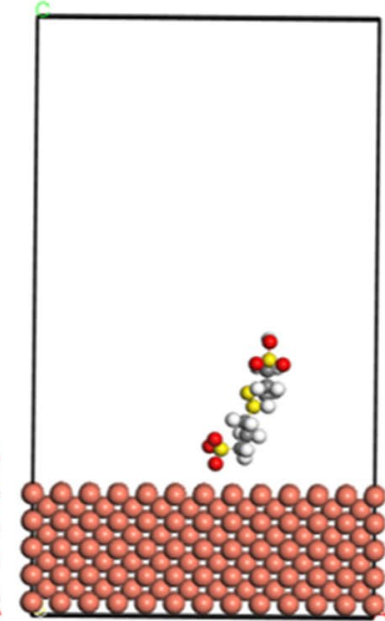

(c) $\mathrm{Cu}\left(\begin{array}{lll}1 & 0 & 1\end{array}\right)$

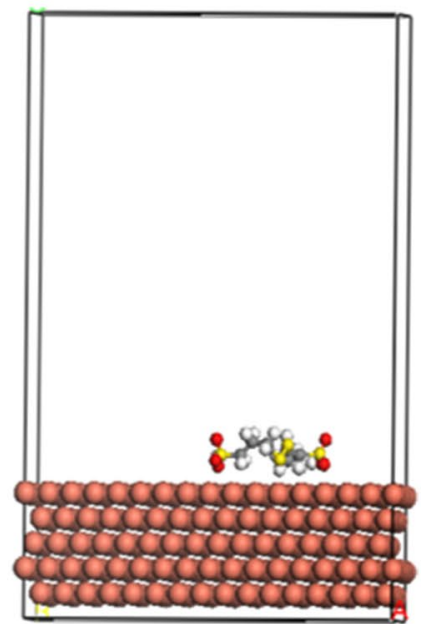

(d) $\mathrm{Cu}\left(\begin{array}{lll}1 & 1 & 1\end{array}\right)$

Figure 4. Configuration of SPS adsorbed on $\mathrm{Cu}(001), \mathrm{Cu}(101)$ and $\mathrm{Cu}$ (111) surface. (a) Side view of initial stage on $\mathrm{Cu}(111)$, (b) side view of equilibrium stage on $\mathrm{Cu}(001)$ surface (c) side view of equilibrium stage on $\mathrm{Cu}$ (101) surface. (d) side view of equilibrium stage on $\mathrm{Cu}$ (101) surface (V/ttps://www.3ds.com/productsservices/biovia/ material studio 6.0).

is vertically adsorbed on the surface of the copper crystal by sulfonic group $\left(\mathrm{SO}_{3} \mathrm{H}\right)$ when in equilibrium on $\mathrm{Cu}$ (101) (Fig. 4c). SPS is adsorbed coplanar to the copper surface by the two MPS groups when in equilibrium on $\mathrm{Cu}$ (111) (Fig. 4d). Since SPS is a commonly employed accelerator, our results suggest that the coplanar adsorption of MPS groups to the copper surface is the main factor contributing to acceleration ${ }^{10,14-16}$.

Figure $5 \mathrm{a}-\mathrm{d}$ show the initial and equilibrium stages for adsorption of SH110. Initially (Fig. 5a), SH110 is located far from the copper surface, suggesting only very slight adsorption. It is vertically oriented and positioned in a sideways V-shape. In equilibriumon, Similar to SPS, SH110 is adsorbed coplanar to the $\mathrm{Cu}(001)$ surface (Fig. 5b). SH110 is Vertically adsorbed on the $\mathrm{Cu}(101)$ surface of the copper crystal by the DHT moiety SH110 is adsorbed coplanar to the copper surface when in equilibrium, but at three points on the molecule: the DHT moiety, the $\mathrm{S}-\mathrm{S}$ bond, and the $-\mathrm{SO}_{3}{ }^{-}$group. The DHT moiety is oriented closest to the surface of the copper, making this group the dominant contributor to this initial (but slight) adsorption.

The equilibrium adsorption of $\mathrm{S}-\mathrm{S}$ and $-\mathrm{SO}_{3}{ }^{-}$groups on the copper surface contribute to the acceleration associated with $\mathrm{SH} 110$ as an additive. Meanwhile, the DHT group adsorbed to the copper surface contributes to $\mathrm{SH} 110$ having an inhibitory effect. Thus, we can conclude that the DHT, S-S, and $-\mathrm{SO}_{3}{ }^{-}$groups are crucial to SH110 adsorption behaviour, which results in fully filled TSVs.

Quantum chemistry calculation. Equilibrium geometry structure. The initial and equilibrium structures of SPS were obtained from MD simulations. To further study how the additives were adsorbed on the copper surface, the initial and adsorbed equilibrium structures of SPS and SH110 were obtained by the DFT B3LYP method, as shown in Figs. 6 and 7.

For SPS in Fig. 6, atoms 1, 5, 6, and 10 are sulfur, while 11-16 are oxygen, and 2, 3, 4, 7, 8, and 9 are carbon. For SH110 in Fig. 7, atoms 2, 3, 8, and 11 are sulfur, 12-14 are oxygen, 5 is nitrogen, and 1, 4, 6, 7, 9, and 10 are carbon.

The optimised bond lengths of SPS and SH110 in initial and equilibrium conditions on the Cu surface were also obtained. For SPS (Table 2), most bonds became longer in equilibrium compared to the initial state, except for $\mathrm{C} 9-\mathrm{S} 10$. It should be noted that the $\mathrm{S}-\mathrm{O}$ bonds changed the most $(\sim 5 \%)$; this suggests that the $\mathrm{SO}_{3}^{-}$group strongly interacts with the $\mathrm{Cu}$ surface. The changes in bond lengths that occur for SH110 from initial 


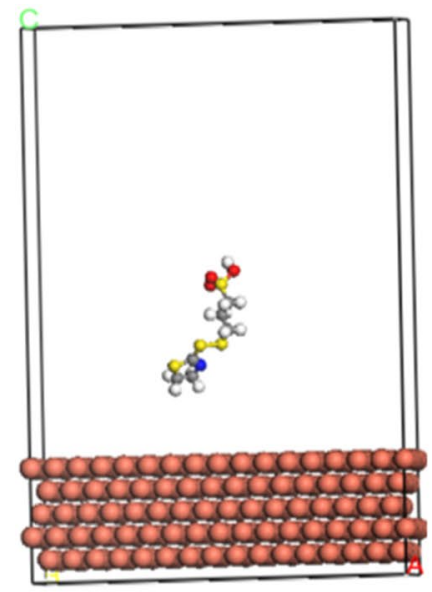

(a) initial

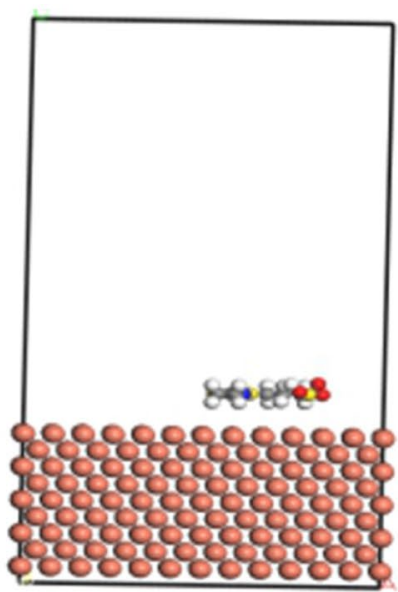

(b) $\mathrm{Cu}\left(\begin{array}{lll}0 & 0 & 1\end{array}\right)$

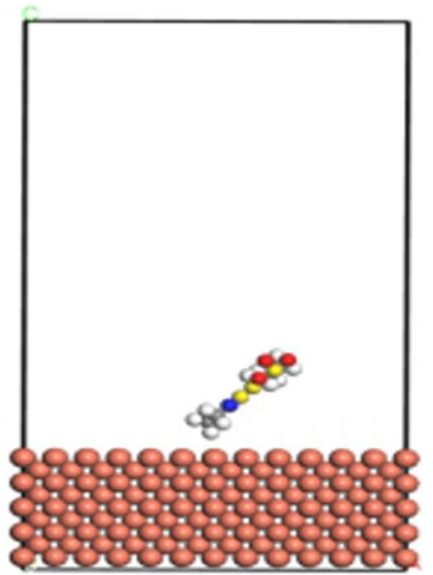

(c) $\mathrm{Cu}\left(\begin{array}{lll}1 & 0 & 1\end{array}\right)$

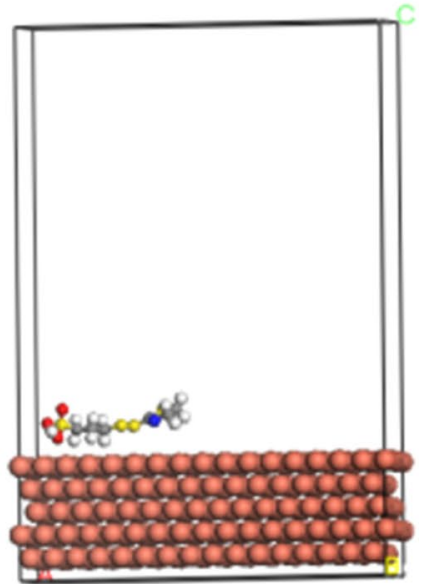

(d) $\mathrm{Cu}\left(\begin{array}{lll}1 & 1 & 1\end{array}\right)$

Figure 5. Configuration of $\mathrm{SH} 110$ adsorbed on $\mathrm{Cu}(001), \mathrm{Cu}(101)$ and $\mathrm{Cu}$ (111) surface. (a) Side view of initial stage on $\mathrm{Cu}(111)$, (b) side view of equilibrium stage on $\mathrm{Cu}(001)$ surface (c) side view of equilibrium stage on $\mathrm{Cu}$ (101) surface. (d) side view of equilibrium stage on $\mathrm{Cu}(101)$ surface ( $\mathbf{V}$ https://www.3ds.com/productsservices/biovia/ material studio 6.0).

a

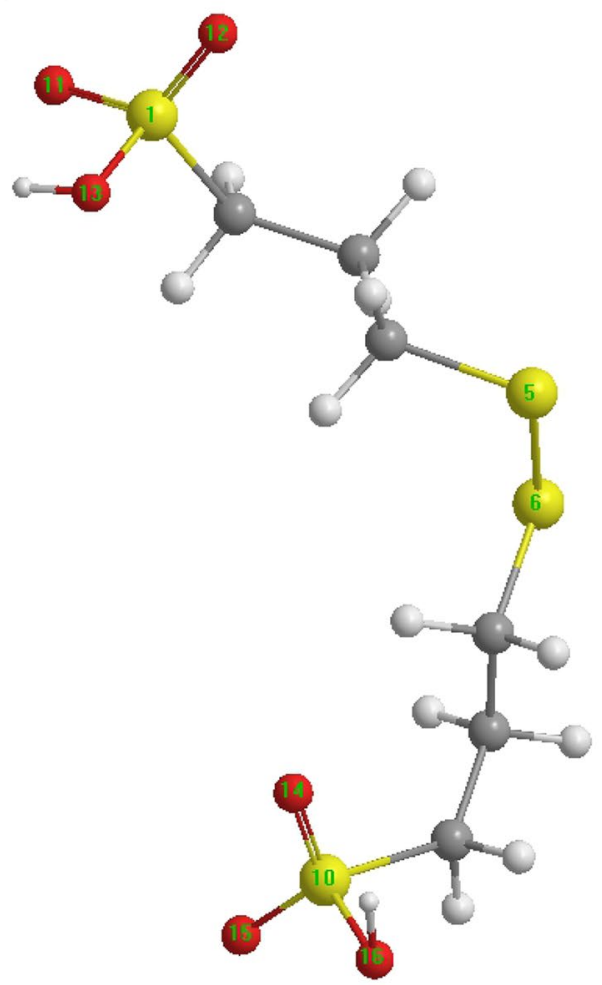

b

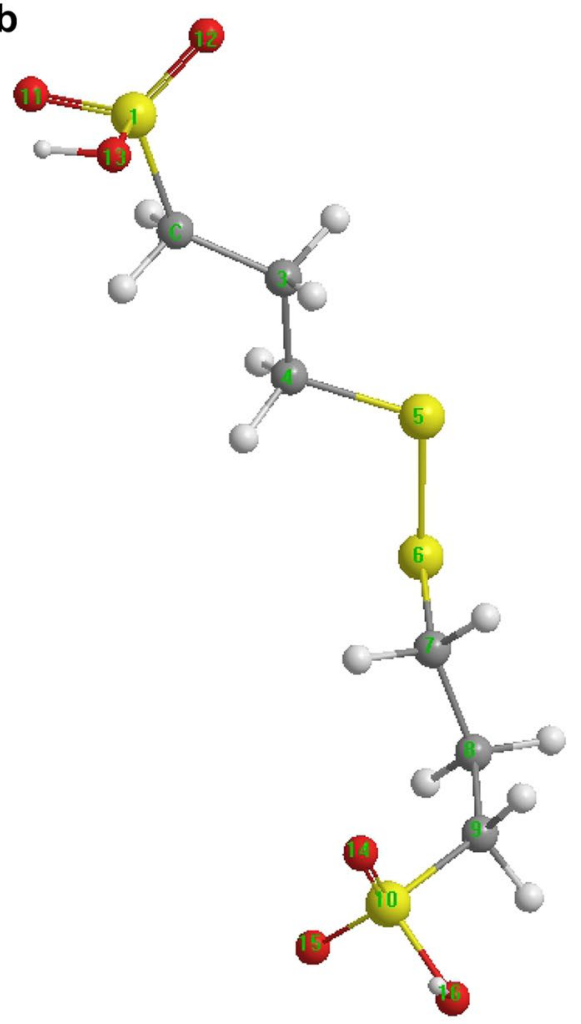

Figure 6. Molecular configuration of SPS from MD simulations. (a) Initial and (b) equilibrium structures ( $\mathbf{V}$ https://www.3ds.com/products-services/biovia/ material studio 6.0).

to equilibrium adsorption are also given in Table 2. For instance, C4-N5 shortens by 13\% upon adsorption, suggesting a strong interaction between the DHT moiety and the copper surface. The C10-S11 bond length also shortens by $\sim 6 \%$ upon adsorption, suggesting that the interaction between the MPS group and copper is also important.

Active sites. To reveal how the groups on each additive interact with the copper surface, an active site was established according to two factors: (1) natural atomic charge and (2) distribution of the frontier molecular 


\section{a}

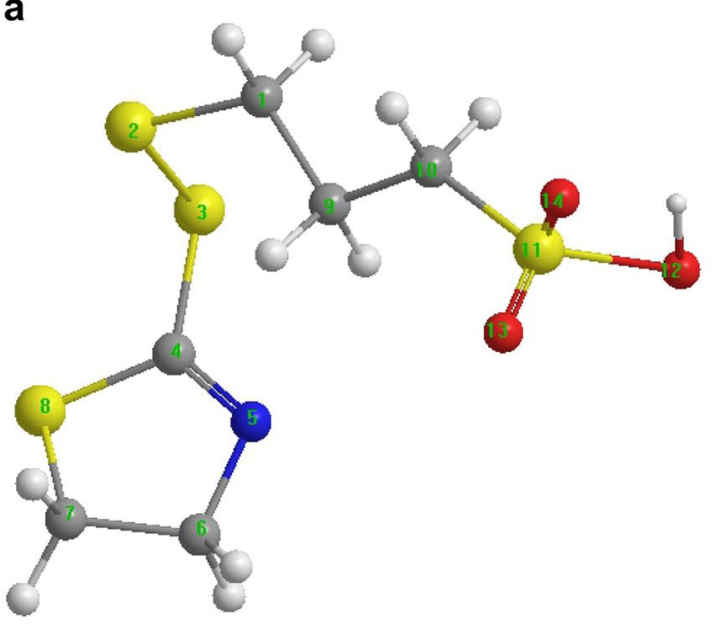

b

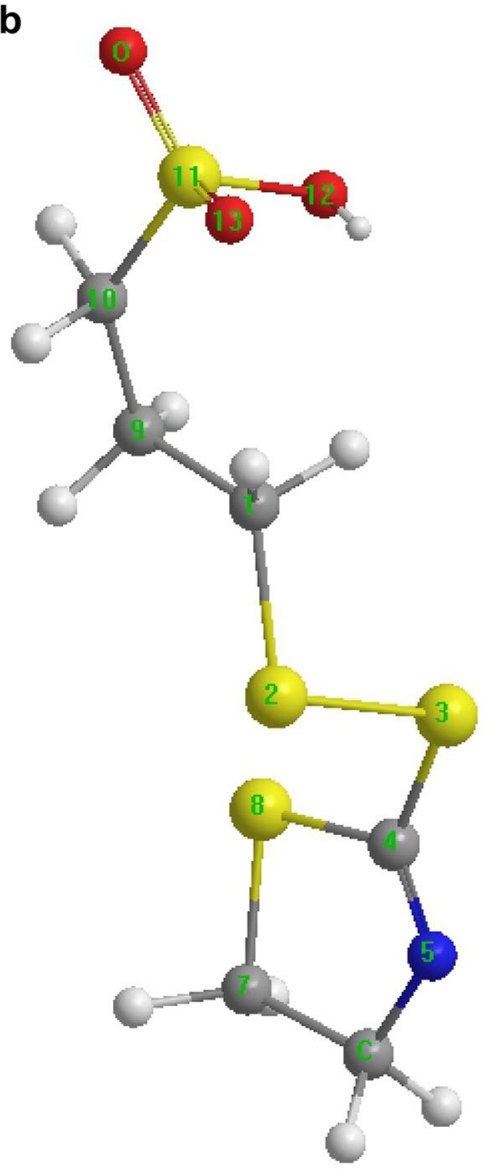

Figure 7. Molecular configuration of SH110 from MD simulations. (a) Initial and (b) equilibrium structures (Vhttps://www.3ds.com/products-services/biovia/ material studio 6.0).

\begin{tabular}{|c|c|c|c|c|c|c|c|}
\hline \multirow[b]{2}{*}{ SPS } & \multicolumn{3}{|l|}{ Bond length } & \multirow[b]{2}{*}{ SH110 } & \multicolumn{3}{|l|}{ Bond length } \\
\hline & Initial (nm) & Equilibrium (nm) & $\begin{array}{l}\text { Change (\%) } \\
\text { (Equilibrium/ } \\
\text { Initial) }\end{array}$ & & Initial (nm) & Equilibrium (nm) & \begin{tabular}{|l|} 
Change (\%) \\
(Equilibrium/ \\
Initial)
\end{tabular} \\
\hline $\mathrm{S} 1-\mathrm{C} 2$ & 0.2606 & 0.2645 & 1.4965464 & $\mathrm{C} 1-\mathrm{S} 2$ & 0.2607 & 0.2659 & 1.9946298 \\
\hline $\mathrm{S} 1=\mathrm{O} 11$ & 0.1974 & 0.2035 & 3.0901722 & $\mathrm{C} 1-\mathrm{C} 9$ & 0.2269 & 0.2209 & -2.6443367 \\
\hline $\mathrm{S} 1=\mathrm{O} 12$ & 0.1971 & 0.2027 & 2.8411974 & S2-S3 & 0.3039 & 0.3052 & 0.4277723 \\
\hline S1-O13 & 0.2288 & 0.2307 & 0.8304196 & S3-C4 & 0.2505 & 0.2418 & -3.4730539 \\
\hline $\mathrm{C} 2-\mathrm{C} 3$ & 0.2206 & 0.223 & 1.087942 & C4-N5 & 0.1918 & 0.1677 & -12.5651721 \\
\hline C3-C4 & 0.2222 & 0.2287 & 2.9252925 & C4-S8 & 0.2487 & 0.2469 & -0.7237636 \\
\hline C4-S5 & 0.2604 & 0.2623 & 0.7296467 & N5-C6 & 0.2133 & 0.2075 & -2.7191749 \\
\hline S5-S6 & 0.2934 & 0.3012 & 2.6584867 & C6-C7 & 0.2275 & 0.2246 & -1.2747253 \\
\hline S6-C7 & 0.2609 & 0.2676 & 2.5680337 & C7-S8 & 0.2565 & 0.2532 & -1.2865497 \\
\hline C8-C9 & 0.2226 & 0.2269 & 1.9317161 & $\mathrm{C} 9-\mathrm{C} 10$ & 0.2186 & 0.2319 & 6.084172 \\
\hline C9-S10 & 0.2693 & 0.2598 & -3.5276643 & C10-S11 & 0.2617 & 0.2528 & -3.4008407 \\
\hline S10-O14 & 0.2036 & 0.2143 & 5.2554028 & S11-O12 & 0.2278 & 0.2243 & -1.5364355 \\
\hline S10-O15 & 0.1972 & 0.2075 & 5.2231237 & $\mathrm{~S} 11-\mathrm{O} 13$ & 0.2015 & 0.1911 & -5.1612903 \\
\hline S10-O16 & 0.2168 & 0.2226 & 2.6752768 & S11-O14 & 0.2011 & 0.1961 & -2.4863252 \\
\hline
\end{tabular}

Table 2. Selected bond lengths for SH110 and SPS. 


\begin{tabular}{|c|c|c|c|c|c|c|c|}
\hline \multirow[b]{2}{*}{ SPS atom } & \multicolumn{2}{|c|}{ Charge (C) } & \multirow[b]{2}{*}{$\Delta \mathrm{C}$} & \multirow[b]{2}{*}{ SH110 atom } & \multicolumn{2}{|c|}{ Charge (C) } & \multirow[b]{2}{*}{$\Delta \mathrm{C}$} \\
\hline & Initial & Equilibrium & & & Initial & Equilibrium & \\
\hline S1 & 0.5466 & 0.4703 & 0.0763 & $\mathrm{C} 1$ & 0.0779 & 0.0488 & 0.0291 \\
\hline $\mathrm{C} 2$ & 0.0309 & 0.0426 & -0.0117 & S2 & -0.0577 & -0.0594 & 0.0017 \\
\hline $\mathrm{C} 3$ & 0.0956 & 0.095 & 0.0006 & S3 & -0.0202 & -0.0071 & -0.0131 \\
\hline $\mathrm{C} 4$ & 0.073 & 0.0835 & -0.0105 & $\mathrm{C} 4$ & -0.0093 & 0.0174 & -0.0267 \\
\hline S5 & -0.0758 & -0.0815 & 0.0057 & N5 & -0.0913 & -0.1448 & 0.0535 \\
\hline S6 & -0.0889 & -0.0921 & 0.0032 & C6 & 0.0762 & 0.0992 & -0.023 \\
\hline C7 & 0.0934 & 0.0974 & -0.004 & C7 & 0.0737 & 0.0543 & 0.0194 \\
\hline $\mathrm{C} 8$ & 0.0956 & 0.1064 & -0.0108 & S8 & -0.0559 & -0.0585 & 0.0026 \\
\hline $\mathrm{C} 9$ & 0.0417 & 0.0467 & -0.005 & C9 & 0.1224 & 0.0958 & 0.0266 \\
\hline S10 & 0.5408 & 0.4154 & 0.1254 & $\mathrm{C} 10$ & 0.0283 & 0.0654 & -0.0371 \\
\hline O11 & -0.3246 & -0.2967 & -0.0279 & S11 & 0.5004 & 0.6034 & -0.103 \\
\hline O12 & -0.2907 & -0.2649 & -0.0258 & O12 & -0.0614 & -0.0749 & 0.0135 \\
\hline $\mathrm{O} 13$ & -0.0661 & -0.0554 & -0.0107 & O13 & -0.2733 & -0.3456 & 0.0723 \\
\hline O14 & -0.3125 & -0.2587 & -0.0538 & O14 & -0.31 & -0.2938 & -0.0162 \\
\hline $\mathrm{O} 15$ & -0.2864 & -0.2534 & -0.033 & & & & \\
\hline O16 & -0.0728 & -0.0545 & -0.0183 & & & & \\
\hline
\end{tabular}

Table 3. Natural atomic charge of SPS and SH110 initially and at equilibrium.

orbitals ${ }^{17}$. This was accomplished by using quantum chemical calculations of the orbital information and the electronic properties.

\section{Natural atomic charge}

Table 3 shows the natural atomic charges of SPS and SH110 initially and at equilibrium. For SPS, O11, O12, $\mathrm{O} 14$, and $\mathrm{O} 15$ carry larger negative charges in the initial state than at equilibrium, and all other atoms exhibit very little change from the initial to equilibrium states. This suggests that $\mathrm{O} 11, \mathrm{O} 12, \mathrm{O} 14$, and $\mathrm{O} 15$ have negative charge centres that could offer electrons to the $\mathrm{Cu}$ atoms to form coordinate bonds that are initially strong, but weaken at equilibrium. S1 and S10 carry large positive charges both in the initial state and at equilibrium, indicating that they possess positive charge centres that can accept electrons from the $3 d$ orbital of the $\mathrm{Cu}$ atoms to form a feedback bond in both states, although this bond would also be weaker in equilibrium than the initial state. This suggests that $\mathrm{SO}_{3}{ }^{-}$is the driving force of the electrostatic interactions and chemical properties of SPS interacting with the $\mathrm{Cu}$ surface. This is one reason $\mathrm{SO}_{3}{ }^{-}$is often present in compounds used as accelerators.

For SH110, N5, O13, and O14 carried larger negative charges in the initial state than at equilibrium. This indicates that $\mathrm{N} 5, \mathrm{O} 13$, and $\mathrm{O} 14$ are negative charge centres that can offer electrons to the $\mathrm{Cu}$ atoms to form coordinate bonds. Moreover, the bonds with N5 and O13 are stronger at equilibrium than in the initial state. S11 carries a positive charge, which indicates a positive charge centre that can accept electrons from the $3 d$ orbital of the $\mathrm{Cu}$ atoms to form coordinate covalent bonds. These S11 bonds are also stronger at equilibrium than in the initial state, further strengthening the interaction of $\mathrm{SH} 110$ with the $\mathrm{Cu}$ surface.

\section{Distribution of the frontier molecular orbitals}

Figure 8 shows the highest occupied and lowest unoccupied molecular orbitals (HOMO and LUMO, respectively) of SPS in both the initial and equilibrium states. We can see that SPS essentially comprises two MPS molecules. The main components of the molecular HOMO and LUMO orbitals are listed in Table 4.

In the initial stage of adsorption, S5, S6, O11, O12, and O13 contribute 86.2\% to the HOMO, with S6 contributing the most (50.50\%). This indicates that the atoms in $\mathrm{S}-\mathrm{S}$ and $\mathrm{SO}_{3}{ }^{-}$play a major role in governing the chemical reactions and can interact strongly with the copper surface. The LUMO is mostly comprised of contributions from C8, C9, S10, O14, O15, and O16, at 9.40\%, 29.52\%, 13.26\%, 10.74\%, 13.55\%, and 7.79\%, respectively. This indicates that SPS can accept electrons from the $3 d$ orbitals of $\mathrm{Cu}$ atoms, thus further strengthening the interaction between SPS and the copper surface.

After adsorption, the frontier molecular orbitals are redistributed. The HOMO is mainly comprised of O15, C9, and S5. This indicates that O15, C9, and S5 can offer electrons; O15 has the maximum electrophilic electron density for charge transfer (76.64\%). Thus, $\mathrm{SO}_{3}{ }^{-}$strongly adsorbs to the copper surface. S1, C3, C4, S5, S6, O11, $\mathrm{O} 12$, and $\mathrm{O} 13$ contribute $90 \%$ of the LUMO, indicating that electrons can be accepted from the $3 d$ orbitals of Cu atoms, further strengthening the interaction of SPS with the copper surface. SPS mainly interacts with the copper surface through the $\mathrm{S}$ and $\mathrm{SO}_{3}{ }^{-}$groups. This may be the reason that SPS is an excellent additive for acceleration.

Figure 9 shows the HOMO and LUMO orbitals of the initial and equilibrium states of SH110. The main components of the HOMO and LUMO orbitals are listed in Table 5. In the initial stage of adsorption, N5 and S8 contribute over $87.74 \%$ to the HOMO. Thus, N5 and S8 can offer electrons. In addition, the DHT moiety plays 
a

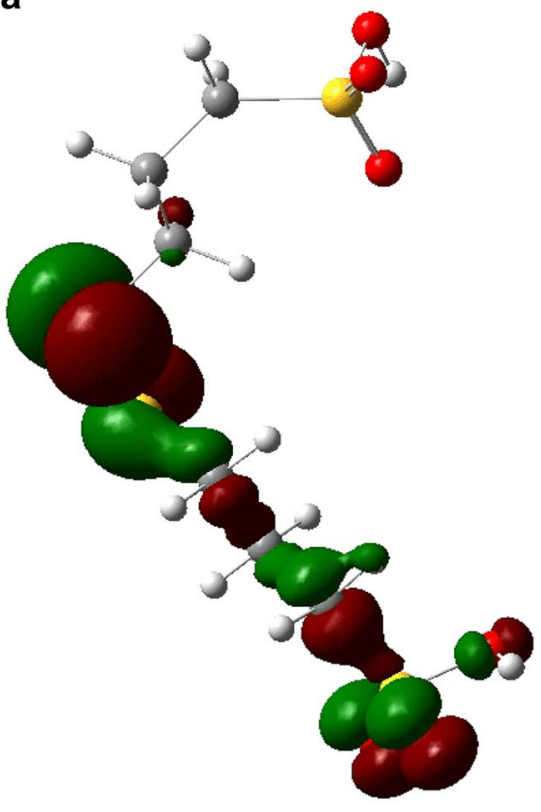

C

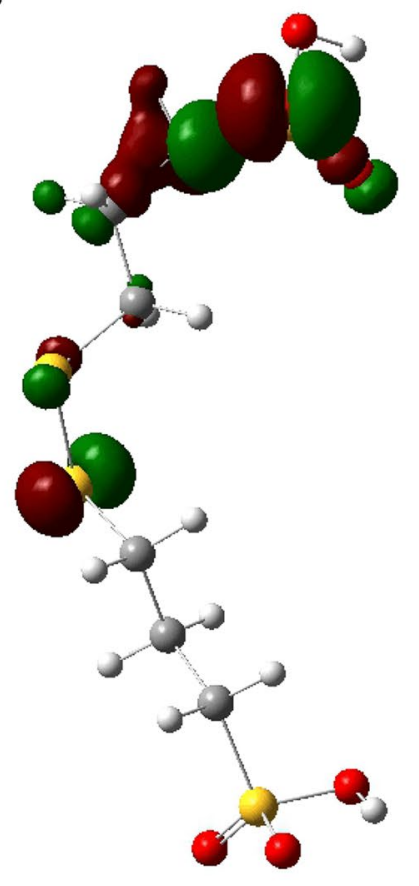

b

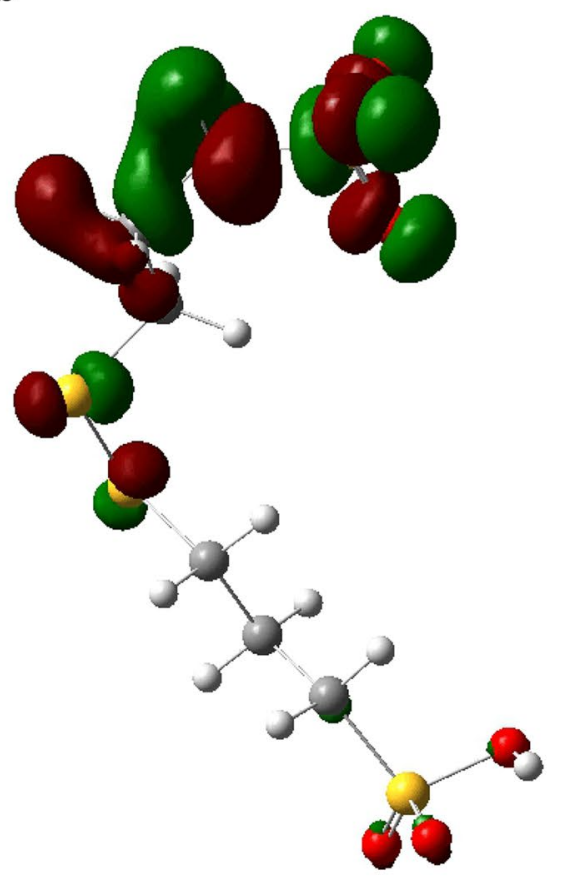

d

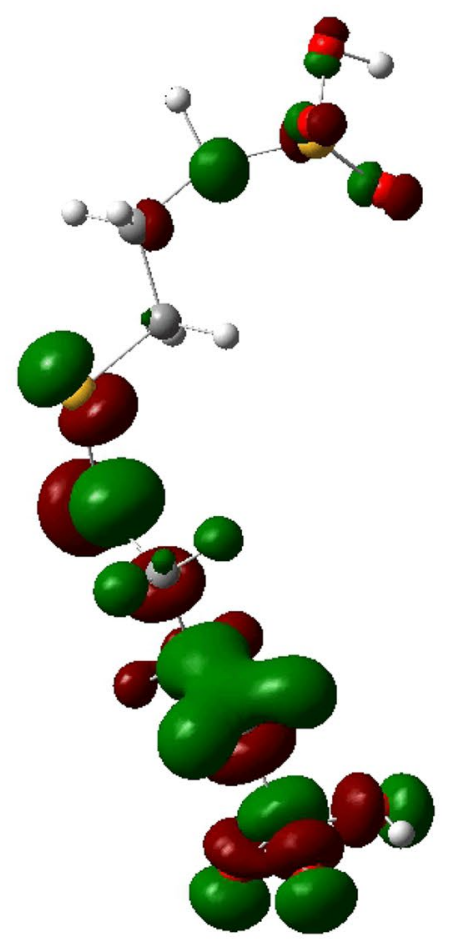

Figure 8. Geometry of SPS. (a) Initial HOMO, (b) initial LUMO, (c) equilibrium HOMO, and (d) equilibrium LUMO (Vhttps://www.3ds.com/products-services/biovia/ material studio 6.0).

a major role in governing chemical reactions and can interact strongly with the copper surface. The LUMO is mainly comprised of $\mathrm{C} 1, \mathrm{~S} 2, \mathrm{C} 9, \mathrm{C} 10, \mathrm{~S} 11, \mathrm{O} 12, \mathrm{O} 13$, and $\mathrm{O} 14$. This indicates that all these atoms have some ability to accept electrons from the $3 d$ orbitals of $\mathrm{Cu}$ atoms, thus further strengthening the interaction of $\mathrm{SH} 110$ with the copper surface. DHT is dominant in the initial stage of adsorption (as shown in Fig. 5), while $\mathrm{SO}_{3}{ }^{-}$has no ability to donate electrons, which differs considerably from SPS. After adsorption to the copper surface, the frontier molecular orbitals are redistributed. N5 and S8 from DHT contribute over 95.49\% to the HOMO in equilibrium, while the atoms associated with the MPS moiety (C9, C10, S11, O12, O13, and O14) do not 


\begin{tabular}{|l|c|l|l|l|}
\hline SPS & \multicolumn{2}{|l|}{ HOMO (\%) } & \multicolumn{2}{l|}{ LUMO (\%) } \\
\hline Stage & Initial & Equilibrium & Initial & Equilibrium \\
\hline S1 & 0.74 & 0 & 0.21 & 11.45 \\
\hline C2 & 5.74 & 0.03 & 0.39 & 2.62 \\
\hline C3 & 1.23 & 0.01 & 0.20 & 9.59 \\
\hline C4 & 2.14 & 0.03 & 0.14 & 8.21 \\
\hline S5 & 10.76 & 5.51 & 1.57 & 12.43 \\
\hline S6 & 50.50 & 1.44 & 2.53 & 7.06 \\
\hline C7 & 0.30 & 0.38 & 0 & 0.37 \\
\hline C8 & 0.05 & 1.43 & 9.40 & 1.30 \\
\hline C9 & 0.05 & 10.62 & 29.52 & 2.01 \\
\hline S10 & 0.01 & 0.87 & 13.26 & 0.02 \\
\hline O11 & 11.51 & 0.07 & 0 & 11.81 \\
\hline O12 & 13.38 & 0.08 & 0.19 & 11.36 \\
\hline O13 & 1.48 & 0 & 0.14 & 7.81 \\
\hline O14 & 0.14 & 2.65 & 10.74 & 1.21 \\
\hline O15 & 0.14 & 76.64 & 13.55 & 0.89 \\
\hline O16 & 0.01 & 0.17 & 7.79 & 0.61 \\
\hline
\end{tabular}

Table 4. Components of SPS molecular orbitals.

a

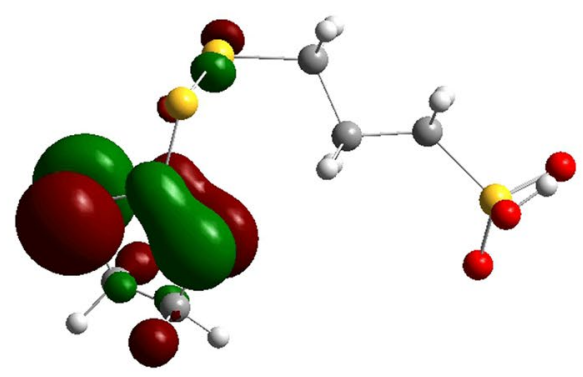

C

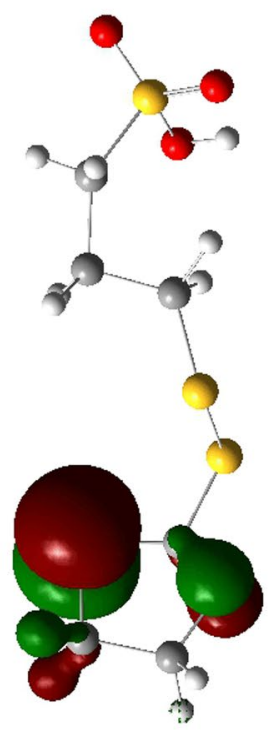

b

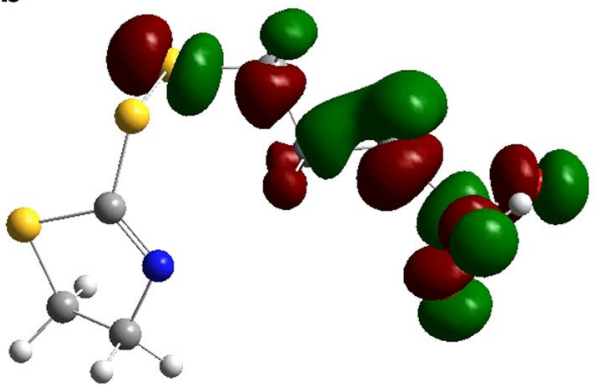

d

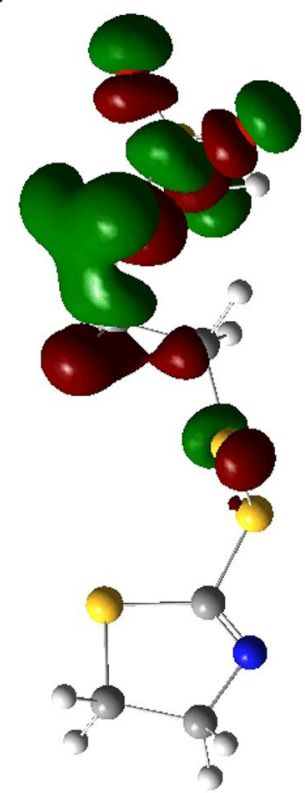

Figure 9. Geometry of SH110. (a) Initial HOMO, (b) initial LUMO, (c) equilibrium HOMO, and (d) equilibrium LUMO (Vhttps://www.3ds.com/products-services/biovia/ material studio 6.0). 


\begin{tabular}{|l|l|l|l|l|}
\hline SH110 & \multicolumn{2}{|l|}{ HOMO (\%) } & \multicolumn{2}{l|}{ LUMO (\%) } \\
\hline Stage & Initial & Equilibrium & Initial & Equilibrium \\
\hline C1 & 0.01 & 0 & 8.31 & 1.41 \\
\hline S2 & 1.83 & 0.17 & 8.42 & 2.92 \\
\hline S3 & 0.71 & 0.48 & 0.33 & 0.51 \\
\hline C4 & 6.03 & 0.72 & 0.01 & 0.02 \\
\hline N5 & 28.06 & 9.55 & 0.01 & 0.04 \\
\hline C6 & 0.52 & 0.11 & 0 & 0 \\
\hline C7 & 0.51 & 0.43 & 0 & 0 \\
\hline S8 & 59.68 & 85.94 & 0 & 0 \\
\hline C9 & 0.014 & 0 & 7.89 & 11.09 \\
\hline C10 & 0 & 0 & 23.15 & 28.73 \\
\hline S11 & 0 & 0 & 12.18 & 13.55 \\
\hline O12 & 0 & 0 & 8.17 & 7.33 \\
\hline O13 & 0 & 0 & 11.31 & 9.09 \\
\hline O14 & 0 & 0 & 10.96 & 13.71 \\
\hline
\end{tabular}

Table 5. Components of SH110 molecular orbitals.

contribute at all to the HOMO. We can therefore conclude that the DHT moiety of SH110 donates electrons to $\mathrm{Cu}$ atoms and becomes strongly adsorbed to the copper surface. At equilibrium, N5 and S8 of the DHT moiety can interact more strongly with the copper surface, enabling SH110 to cover the copper surface and prevent further deposition. This may be the reason that $\mathrm{SH} 110$ is an excellent additive that provides an inhibitory effect. The MPS moiety $(\mathrm{C} 1, \mathrm{~S} 2, \mathrm{~S} 3, \mathrm{C} 9, \mathrm{C} 10, \mathrm{~S} 11, \mathrm{O} 12, \mathrm{O} 13$, and O14) contributes to the LUMO, indicating that this portion of $\mathrm{SH} 110$ can accept electrons from the $3 d$ orbitals of $\mathrm{Cu}$ atoms, further strengthening the interaction of SH110 with the copper surface. This is likely the reason that SH110 behaves as an excellent additive for acceleration. Therefore, SH110 is unique in that the DHT moiety provides an inhibitory effect for TSV filling, while the MPS moiety acts as an accelerator. SH110 exhibits an optimal balance between acceleration and suppression that allows for void-free TSV filling.

\section{Materials and methods}

All chemical additives of SH110 and SPS were purchased from Jiangsumengde. SH110 and SPS are unstable in their acid forms, whereas the sodium salts are stable. Therefore, in the current study, we utilised the sodium salts of SPS and SH110 in acidic solution to obtain the corresponding acid in situ; the sodium salts were used for MD simulations as well.

The acidic and sodium salt forms of $\mathrm{SH} 110$ contain $\mathrm{S}-\mathrm{S}$ bonds, $\mathrm{SO}_{3}^{-}$groups (with $\mathrm{H}^{+}$or $\mathrm{Na}^{+}$, respectively), and DHT within their frameworks (Fig. 10a-c). Accelerators commonly contain $\mathrm{S}-\mathrm{S}$ and $\mathrm{SO}_{3}{ }^{-18}$, and both are present in the acidic and sodium salt forms of SPS (Fig. 10d,e), which is a valuable accelerator ${ }^{10,14-16}$. Notably, DHT is commonly added during TSV filling as a leveller ${ }^{7,8}$, so the SH110 additive is expected to provide both accelerator and leveller properties. The MPS molecule in Fig. $10 \mathrm{f}$ corresponds to one half of a SPS molecule.

Electroplating. The primary solution prepared for electroplating consisted of $0.78 \mathrm{~mol} / \mathrm{L} \mathrm{CuSO} \cdot 5 \mathrm{H}_{2} \mathrm{O}$, $0.2 \mathrm{~mol} / \mathrm{L} \mathrm{H}_{2} \mathrm{SO}_{4}$, and $0.2 \mathrm{~g} / \mathrm{L} \mathrm{KCl}$. A single-component additive (SH110 or SPS) was then added to the primary solution without a suppressor or leveller.

A silicon chip with TSV (diameter $20 \mu \mathrm{m}$ and depth $60 \mu \mathrm{m}$ ) was used for electroplating. A blind via was etched by Bosch-type deep reaction ion etching (DRIE). A silicon dioxide layer of approximately $0.3 \mu \mathrm{m}$ was deposited for sidewall insulation using tetraethoxysilane chemical vapor deposition (TEOS CVD), and then a copper seed layer was deposited through a physical vapor deposition (PVD) process.

During electrodeposition, the TSV sample was first immersed in deionized water in a vacuum chamber for $10 \mathrm{~min}$, and then placed in an ultrasonicator for $60 \mathrm{~s}$ to remove air and impurities. After this pre-processing, the TSV sample was immersed in the plating solution for $10 \mathrm{~min}$ to allow the equilibration state to be reached between the additive and copper in the vias prior to electroplating. TSV filling was carried out with either SH110 or SPS additive in the primary solution, at a current density of $1 \mathrm{~mA} / \mathrm{cm}^{2}$. After electrodeposition, the cross-section and microstructure of the TSVs were observed using SEM at $2000 \times$ magnification (TESCAN MIRA3LMU).

Electrochemical procedures. To study the electrochemical properties of the additives in the deposition process for TSV filling, LSV ${ }^{19,20}$ was performed on an electrochemical workstation (Chenhua CHI660E) using a three-electrode cell. The cell consisted of a 5-mm-diameter rotating Pt disk electrode (Pt-RDE) as the working electrode (WE), a Pt counter electrode (CE), and a saturated calomel electrode (SCE) as the reference. The testing potential ranged from 0.6 to $0.7 \mathrm{~V}$ versus Pt-RDE with a scan rate of $5 \mathrm{mV} / \mathrm{s}$. The LSV measurements were performed using a potentiostat/galvanostat (PARSTAT 2273) at $25^{\circ} \mathrm{C}$. 
a<smiles>O=S(=O)(O)CCCSSC1=NCCS1</smiles>

3-(2-(4,5-dihydrothiazol-2-yl)disulfanyl)
propane-1-sulfonic acid

d<smiles>O=S(=O)(O)CCCSSCCCS(=O)(=O)O</smiles>

bis-3-sulfopropyl-disulfonic acid b

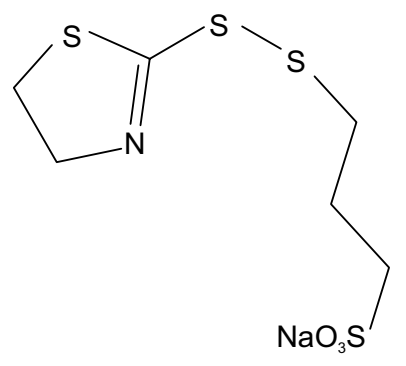

sodium 3-(2-(4,5-dihydrothiazol-2-yl) disulfanyl)propane-1-sulfonate

e<smiles>O=S(=O)(CCCSSCCCS(=O)(=O)O[Na])O[Na]</smiles>

bis-(sodium-sulfopropyl)-disulfide
C<smiles>C1=NCCSC1</smiles>

4,5-dihydrothiazole

Figure 10. Chemical formulas of SH110 and SPS used in this study. (a) SH110; acidic form, (b) SH110; sodium salt, (c) 4,5-dihydrothiazole (DHT), (d) SPS; acidic form, (e) SPS; sodium salt, and (f) 3-mercaptopropane sulfonate (MPS).

Theory and computational details. MD simulations were performed using Materials Studio software (Vhttps://www.3ds.com/products-services/biovia/ material studio 6.0 ${ }^{21}$ in order to understand the adsorption behaviour of SPS and SH110 on a Cu (111) surface in a simulation box $(2.0448 \times 1.0224 \times 3.5435 \mathrm{~nm})$ with periodic boundary conditions. These parameters allowed a representative part of the interface to be modelled without arbitrary boundary effects. The simulation box consisted of a copper slab with a 2.5 -nm-high vacuum layer on top. The crystals in the slab were cut along the (111) plane, keeping the uppermost and lowest layers released and the inner layer fixed. The simulation was carried out using an NVT/NVE ensemble, where the system atomic number $(\mathrm{N})$, volume $(\mathrm{V})$, and energy (E) remained unchanged. The simulation was carried out below $298 \mathrm{~K}$, with the time step and simulation time set to $0.1 \mathrm{fs}$ and $500 \mathrm{ps}$, respectively. The force field COMPASS was used for the entire simulation procedure.

Quantum chemistry calculations. Quantum chemical calculations $s^{7,16,22}$ were performed by the DMol ${ }^{3}$ module of Materials Studio. Complete geometries of the additives were fully optimised without any symmetry constraints using B3LYP/6-31G (d, p) with GAUSSIAN $09 \mathrm{~W}$.

\section{Conclusions}

The single-component additive SH110 was used for TSV copper electroplating, resulting in void-free TSV filling. The electrochemistry of SH110 indicates that it acts to both accelerate and suppress, with suppression that is better than that of the conventional additive, SPS. SH110 exhibits better bottom-up filling ability than SPS over a wider potential range. According to MD simulations, the main factor contributing to acceleration is the coplanar orientation of the MPS moiety of SH110 adsorbed to the copper surface. SH110 can be adsorbed to the Cu surface by the DHT and MPS moieties, while SPS- which essentially contains two MPS molecules-is adsorbed to the Cu surface only by MPS moieties. Quantum chemistry calculations show that in SH110, the DHT moiety provides an inhibitory effect for TSV filling, while the MPS acts as an accelerator. SH110 is therefore an excellent additive exhibiting both acceleration and suppression, which proves useful in achieving void-free TSV filling. Thus, we may use SH110 for TSV filling in 3D integration in further work.

\section{Data availability}

All data generated or analysed during this study are included in this published article.

Received: 22 April 2020; Accepted: 20 May 2021

Published online: 08 June 2021 


\section{References}

1. Koyanagi, M. et al. Three-dimensional integration technology based on wafer bonding with vertical buried interconnections. IEEE Trans. Electron. Devices 53, 2799-2808 (2006).

2. Kawano, M. Three-dimensional packaging technology for stacked DRAM with 3-Gb/s data transfer. IEEE Trans. Electron. Devices 55, 1614-1620 (2008).

3. Morrow, P. R., Park, C.-M., Ramanathan, S., Kobrinsky, M. J. \& Harmes, M. Three-dimensional wafer stacking via Cu-Cu bonding integrated with 65-nm strained-Si/low-k CMOS technology. IEEE Electron. Device. Lett. 27, 335-337 (2006).

4. Pasquale, M. A., Gassa, L. M. \& Arvia, A. J. Copper electrodeposition from an acidic plating bath containing accelerating and inhibiting organic additives. Electrochim. Acta 53, 5891-5904 (2008).

5. Andricacos, P. C., Uzoh, C., Dukovic, J. O., Horkans, J. \& Deligianni, H. Damascene copper electroplating for chip interconnections. IBM J. Res. Dev. 42, 567-574 (1998).

6. Brennan, R., Phillips, M. M., Yang, L. Y. O. \& Moffat, T. P. Characterization and purification of commercial SPS and MPS by ion chromatography and mass spectrometry. J. Electrochem. Soc. 158, D178-D186 (2011).

7. Chang, C., Lu, X., Lei, Z., Wang, Z. \& Zhao, C. 2-Mercaptopyridine as a new leveler for bottom-up filling of micro-vias in copper electroplating. Electrochim. Acta 208, 33-38 (2016).

8. Broekmann, P. et al. Classification of suppressor additives based on synergistic and antagonistic ensemble effects. Electrochim. Acta 56, 4724-4734 (2011).

9. Hai, N. T. M. et al. Beyond interfacial anion/cation pairing: the role of $\mathrm{Cu}(\mathrm{I})$ coordination chemistry in additive-controlled copper plating. Electrochim. Acta 83, 367-375 (2012).

10. Gallaway, J. W., Willey, M. J. \& West, A. C. Acceleration kinetics of PEG, PPG, and a triblock copolymer by SPS during copper electroplating. J. Electrochem. Soc. 156, D146-D154 (2009).

11. Tang, J. et al. Copper bottom-up filling for through silicon via (TSV) using single JGB additive. ECS Electrochem. Lett. 4, D28-D30 (2015).

12. Cao, H., Hang, T., Ling, H., Gao, L. \& Li, M. Linear sweep voltammetric study on the copper electrodeposition of though-siliconvias. J. Electrochem. Soc. 161, D349-D352 (2014).

13. Josell, D. \& Moffat, T. P. Superconformal bottom-up nickel deposition in high aspect ratio through silicon vias. J. Electrochem. Soc. 163, D322-D331 (2016).

14. Hai, N. T. M. et al. Competitive anion/anion interactions on copper surfaces relevant for Damascene electroplating. Electrochim. Acta 70, 286-295 (2012).

15. Dow, W. P., Chiu, Y. D. \& Yen, M. Y. Microvia filling by Cu electroplating over a Au seed layer modified by a disulfide. J. Electrochem. Soc. 156, D155-D167 (2009).

16. Lei, Z., Chen, L., Wang, W., Wang, Z. \& Zhao, C. Tetrazole derived levelers for filling electroplated Cu microvias: electrochemical behaviors and quantum calculations. Electrochim. Acta 178, 546-554 (2015).

17. Karelson, M., Lobanov, V. S. \& Katritzky, A. R. Quantum descriptors in QSAR/QSPR studies. Chem. Rev. 96, 1027-1044 (1996).

18. Moffat, T. P., Wheeler, D., Huber, W. H. \& Josell, D. Superconformal electrodeposition of copper. Electrochem. Solid-State Lett. 4, C26-C29 (2001)

19. Cao, H., Hang, T., Ling, H. \& Luo, W. Study on the behaviors of Cu filling in special through-silicon-vias by the stimulation of electric field distribution. Microelectron. Eng. 116, 1-5 (2014)

20. Tsai, T. H. \& Huang, J. H. Electrochemical investigations for copper electrodeposition of through-silicon via. Microelectron. Eng. 88, 195-199 (2011).

21. Wang, C., Zhang, J., Yang, P. \& An, M. Through-hole filling by copper electroplating using sodium thiazolinyl-dithiopropane sulfonate as the single inhibitor. Int. J. Electrochem. Sci. 7, 10644-10651 (2012).

22. Wang, C., An, M., Yang, P. \& Zhang, J. Prediction of a new leveler ( $N$-butyl-methyl piperidinium bromide) for through-hole electroplating using molecular dynamics simulations. Electrochem. Commun. 18, 104-107 (2012).

\section{Acknowledgements}

The work was supported by the China Department of Science \& Technology Program 973 (Grant No. 2015CB057202). The funding agency had no role in the study design, the collection, analysis, or interpretation of data, the writing of the report, or the decision to submit the article for publication.

\section{Author contributions}

Y.L., F.W. wrote the main manuscript text and prepared all the figures.

\section{Competing interests}

The authors declare no competing interests.

\section{Additional information}

Correspondence and requests for materials should be addressed to Y.L.

Reprints and permissions information is available at www.nature.com/reprints.

Publisher's note Springer Nature remains neutral with regard to jurisdictional claims in published maps and institutional affiliations.

Open Access This article is licensed under a Creative Commons Attribution 4.0 International License, which permits use, sharing, adaptation, distribution and reproduction in any medium or format, as long as you give appropriate credit to the original author(s) and the source, provide a link to the Creative Commons licence, and indicate if changes were made. The images or other third party material in this article are included in the article's Creative Commons licence, unless indicated otherwise in a credit line to the material. If material is not included in the article's Creative Commons licence and your intended use is not permitted by statutory regulation or exceeds the permitted use, you will need to obtain permission directly from the copyright holder. To view a copy of this licence, visit http://creativecommons.org/licenses/by/4.0/.

(C) The Author(s) 2021 